\title{
SABERES LOCAIS COMO ALTERNATIVAS DE CONSERVAÇÃO AMBIENTAL
}

\author{
Neila de Jesus Ribeiro Almeida ${ }^{1}$ \\ Dulcidéia da Conceição Palheta ${ }^{2}$
}

\begin{abstract}
RESUMO
As discussões sobre a conservação ambiental ganharam destaque ao longo do século 20, mas, sobretudo, no início dos anos 2000 esses debates tomaram força com a instituição do Sistema Nacional de Unidades de Conservação-SNUC, partindo da ideia de que para proteger a biodiversidade não é necessário que a mesma esteja intocada, mas que seja manejada de forma sustentável por todas as populações que habitam tradicionalmente a área. Nesse sentido, este artigo, a partir de pesquisa de campo utilizando instrumentos do método etnográfico, procura compreender os modos de vida da população residente em Unidades de Conservação no lago da Usina Hidrelétrica de Tucuruí no estado do Pará. "Focado" exclusivamente na Reserva de Desenvolvimento Sustentável Alcobaça, em um contexto rural a partir do cultivo de diversificadas espécies nativas, em um cenário já fortemente impactado pelo empreendimento hidrelétrico, analisou-se as maneiras de uso e acesso a recursos comuns, considerando os saberes e prática locais a partir do contexto da conservação ambiental.
\end{abstract}

Palavras-chave: Conservação Ambiental. Modos de Vida. Recursos Comuns.

\begin{abstract}
Discussions on environmental conservation were highlighted throughout the $20^{\text {th }}$ century, but especially in the early 2000 s these debates took force with the establishment of the National System of Conservation SNUC units, based on the idea that to protect biodiversity, it is not necessary it to be untouchable, but that it must be managed in a sustainable manner for all populations who traditionally inhabit the area. In this sense this article, from field research by using instruments of the ethnographic method, seeks to understand the ways of life of people living in protected areas in the lake of the Tucuruí hydroelectric plant in the state of Pará. Pointer exclusively on the Sustainable Development Reserve Alcobaça in a rural context from the cultivation of diverse native species, in a scenario already heavily impacted by hydropower development, analyzis was performed on the ways of use and access to common resources, considering the knowledge and local practices from the context of environmental conservation.
\end{abstract}

Keywords: Environmental Conservation. Livelihoods. Common resources.

\section{INTRODUÇ̃̃̃O}

A utilização desenfreada dos recursos naturais compromete a diversidade biológica e social principalmente pela distorção nas formas de uso e acesso a esses recursos. Tal distorção reflete os atuais modelos de desenvolvimento que desconsideram os limites impostos pela natureza, seus ciclos e processos de resiliência Para esta problemática desenhada ao longo dos

${ }^{1}$ Doutora em Ecologia Aquática e Pesca (PPGEAP/UFPA). Coordenadora do Núcleo Universitário de São Caetano de Odivelas (NUSC/UFPA). Discente do curso de especialização em Geografia e Meio Ambiente da Universidade Federal do Pará campus de Ananindeua. E-mail: neilalmeida2000@hotmail.com

2 Doutora em Ciências Biológicas (UFPA). Professora adjunto da Universidade Federal Rural da Amazônia (UFRA). E-mail: deiapalheta@hotmail.com 
anos e agigantada no início do século XXI, medidas estão sendo tomadas na tentativa da conservação da sociobiodiversidade. Nesse sentido, o sistema jurídico brasileiro, tenta de alguma forma mitigar a exploração dos recursos através da Lei 9.985 de 18 de Julho de 2000 que cria o Sistema Nacional de Unidades de Conservação na tentativa de organizar os espaços territoriais e potencializar o manejo de recursos.

Porém, embora as políticas públicas tendam a priorizar as práticas voltadas à proteção da densidade biológica e social, o modelo utilizado para este fim ainda não consegue seguir os objetivos para a conservação. Entre as falhas do sistema, podem ser percebidas as maneiras como são conduzidas as práticas "modernas" desenvolvidas na agricultura. As formas de cultivos com alta tecnologia que priorizam a produção, não conseguem se enquadrar nos objetivos das Unidades de Conservação de Uso Sustentável, onde os conhecimentos tradicionais das populações locais não são levados em consideração como deveriam, desconsiderando uma experiência próxima.

É esta experiência próxima que fornece o amálgama de um saber, que é transferido de geração a geração privilegiadamente por via oral, a partir da construção imaginária de cartografia, que fortalece a noção de território ou espaço onde o grupo se reproduz econômica e socialmente, além de ocupar esse território por várias gerações, ainda que alguns membros individuais possam ter-se deslocado para os centros urbanos e voltado para a terra dos seus antepassados. (FERNANDES; FERNANDES, 2015 p.138)

Esses fatores são potencializados quando as espécies cultivadas são armazenadas em bancos de germoplasma, fomentando estratégias para a proposição e implementação da monocultura e, sobretudo, desconsiderando a função dos agricultores tradicionais no manejo das espécies (SANTILLI, 2009). Além desses fatores, o sistema agrícola tradicional é ameaçado pelo agronegócio que utiliza imensas áreas de terras no cultivo de uma única espécie visando apenas atender o mercado e ameaçando a diversidade de práticas e modos de ser e viver locais.

A implantação de grandes projetos no Brasil, especialmente na Amazônia, trás vastas alterações nas paisagens, as terras de pequenos agricultores são compradas e transformadas em gigantescos empreendimentos com impactos irreparáveis. Entre esses empreendimentos, destacam-se as usinas hidrelétricas onde grandes áreas são inundadas ocasionando tragédias socioambientais para toda a região. No rio Tocantins, estado do Pará, está implantada a usina hidrelétrica de Tucuruí que desde seu funcionamento na década de 80 , além dos inúmeros impactos ambientais ocorridos na biodiversidade, a população atingida pelo empreendimento vem tentando se readequar sem deixar seus modos tradicionais de vida. 
Durante a fase de construção da hidrelétrica, cerca de 20 anos, a ocupação das áreas não cessava, porém no início dos anos 80 com a conclusão das obras da primeira fase o cenário da região do entorno da barragem era outro. Houve a formação de um grande lago (Figura 1) e as famílias que residiam na área alagada foram deslocadas para áreas rurais, em vilas que foram implantadas para abrigar exclusivamente as famílias que compulsoriamente foram deslocadas das suas casas. Considerando esse contexto de mudança de locais de residências das famílias que viviam antes da implantação da usina em área de rios, e agora em áreas bem distantes da sua realidade. Essas populações ribeirinhas ${ }^{3}$, que "vivia da pesca e da pequena agricultura, teve que se adaptar aos loteamentos rurais longe dos rios e passar a sobreviver exclusivamente das atividades da agricultura" (ALMEIDA; FERNANDES; CAÑETE, 2015).

Essas interações complexas repercutem principalmente nos modos de uso e acesso ao cultivo, partindo das regras impostas no modelo de Unidades de Conservação. Nesses cenários disciplinados pelo SNUC, muitas comunidades não podem colocar em prática a diversidade agrícola que marcou e marca sua trajetória como população tradicional, pois o modelo tecnológico capitalista domina o sistema impondo outras lógicas. Para entender tais contextos vale reportar-se à Tragédia dos Comuns de Hardin (1968).

\footnotetext{
${ }^{3}$ Populações Ribeirinhas: Diegues e Arruda (2000) e Diegues (2001) categorizando populações tradicionais destacam o caboclo/ribeirinho amazônico, que neste trabalho será chamado de populações ribeirinhas, como aquelas populações que vivem nas várzeas e beiras de rio, dependendo fundamentalmente da pesca. Vivem, principalmente, à beira de igarapés, igapós, lagos e várzeas. Mesclam suas atividades pesqueiras com pequenas agriculturas (mandioca, milho e arroz) e com o extrativismo vegetal (castanha-do-pará, açaí e palmito). Ratificado por Pereira (2007) que destaca que as comunidades ribeirinhas do Solimões-Amazonas vivem da pesca e alternam suas atividades com a agricultura e o extrativismo vegetal. Assim como Cañete e Cañete (2010) discutem criticamente o conceito de população tradicional, destacando a população ribeirinha do rio Purus como aquela que desenvolve diversas atividades (pesca, agricultura e extrativismo) durante o ano inteiro.
} 


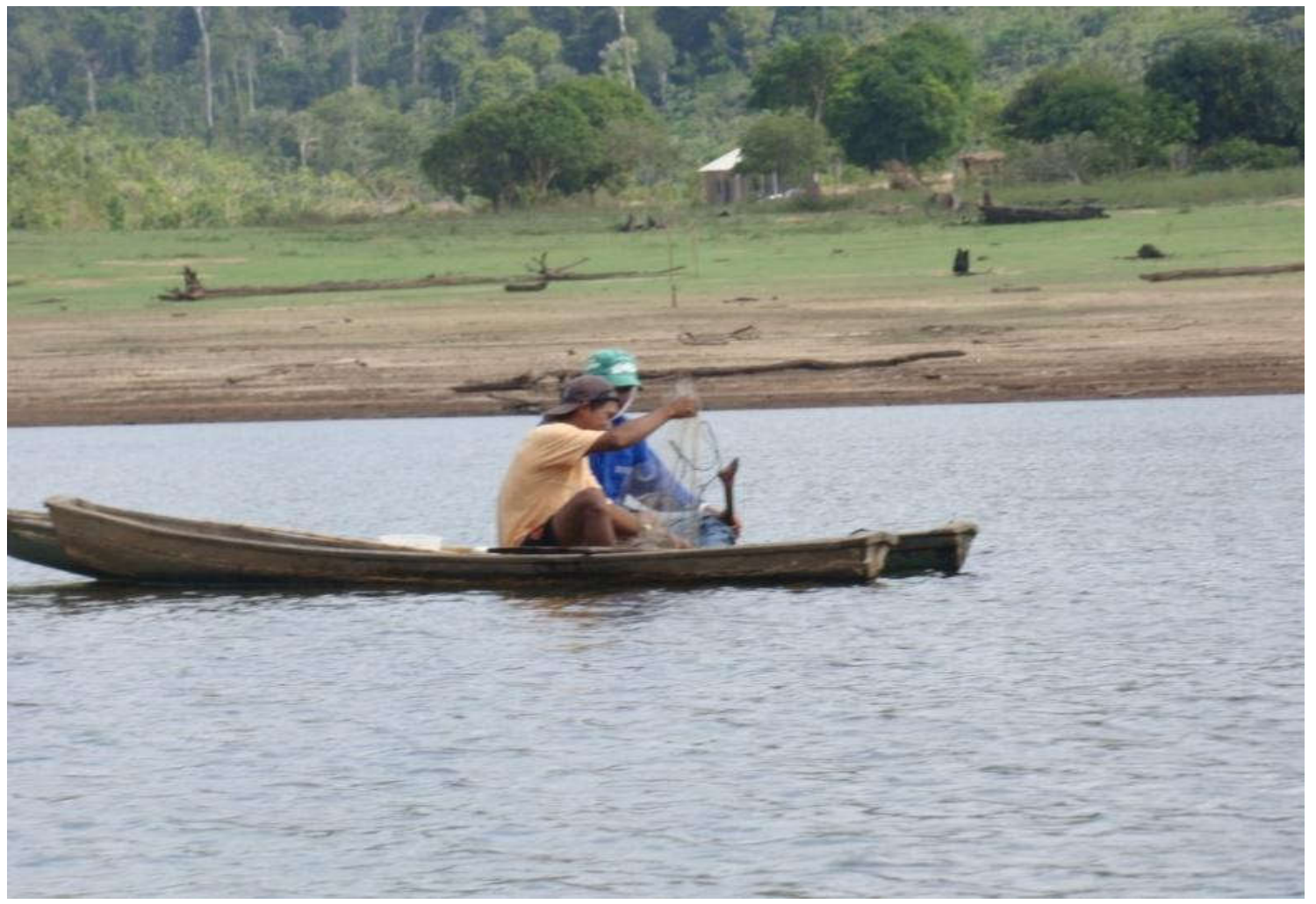

Certamente, o aumento da população levaria à exaustão no uso dos recursos naturais, dado que o mesmo obedeceria a um modelo de livre acesso aos recursos comuns (considerando os recursos naturais como recursos comuns), demandando do Estado ou do setor privado o controle sobre os mesmos. Porém, a obra de Feeny et. al. (1990), trouxe a discussão de 4 modelos de uso dos recursos comuns que amplia e demonstra que possibilidades alternativas são viáveis e existem. Contra argumentando Hardin (1968), a partir de dados coletados em diversos continentes, o autor apresenta quatro arranjos de regulação para o acesso e uso dos recursos naturais, a saber: livre acesso (direitos de propriedade não definidos, ou sem nenhum tipo de regulação), o privado (o uso do recurso ou as regras para tanto seriam definidas exclusivamente pelo indivíduo ou grupo reconhecidos pelo governo como proprietários), o comunal (onde os recursos seriam manejados por comunidade que vive diretamente desses recursos excluindo a presença de indivíduos externos) e a estatal (aquele na qual o direito ao uso do recurso seria exclusivo ao Governo, assim como as regras para a definição de uso dos mesmos).

Partindo dessas abordagens e com dados do contexto da UHE de Tucuruí, este texto descreve e traz reflexões relativas ao acesso e uso dos recursos naturais, na condição de recursos comuns, desenvolvido por uma população local no interior do lago da Usina 
Hidrelétrica de Tucuruí. Estas podem ser entendidas como práticas de conservação ambiental em uma tentativa de desenho de um modelo misto de manejo comunal ou estatal, considerando como um conceito muito próximo de agrobiodiversidade.

As dinâmicas e complexas relações entre as sociedades humanas, as plantas cultivadas e os ambientes em que vivem, repercutindo sobre as políticas de conservação dos ecossistemas cultivados, de promoção da segurança alimentar e nutricional das populações humanas, de inclusão social e de desenvolvimento local sustentável (SANTILLI, 2009 p.91).

\section{1. ÁREA DE ESTUDO}

A região que as pesquisas de campo foram desenvolvidas é a Reserva de Desenvolvimento Sustentável Alcobaça, que está localiza no estado do Pará nos municípios de Tucuruí e Novo Repartimento (Mapa 01). Essa reserva foi criada sob a Lei Estadual $\mathrm{N}^{\circ}$ 6.451 de 08 de Abril de 2002 instituída pela Secretaria Estadual de Meio Ambiente, tendo como objetivo a conservação da biodiversidade degradada pela implementação da Usina Hidrelétrica de Tucuruí-UHT, e para atenuar os múltiplos conflitos territoriais locais, decorrentes da implantação deste empreendimento (ARAÚJO; ROCHA, 2008). Essa unidade de conservação recebeu esse nome em homenagem a antiga vila de Alcobaça que recebeu projetos ali instalados e inconclusos, tais como a estrada de ferro e a construção da hidrelétrica do Tucuruí. O nome dado a região, antes da criação da reserva, era região do Caraipé, sendo que até hoje, os moradores mais antigos denominam a região de Caraipé e não de Alcobaça (ALMEIDA, CAÑETE, 2015).

De acordo com o SNUC em seu artigo $20^{\circ}$ destaca que uma Reserva de Desenvolvimento Sustentável (RDS), unidade de conservação de uso sustentável, se caracteriza por ser uma área natural que abriga populações tradicionais, cuja existência baseia-se em sistemas sustentáveis de exploração dos recursos naturais, desenvolvidos ao longo de gerações e adaptados às condições ecológicas locais e que desempenham um papel fundamental na proteção da natureza e na manutenção da diversidade biológica. As reservas de desenvolvimento sustentável têm como principal objetivo preservar a natureza e, ao mesmo tempo, assegurar as condições e os meios necessários para a reprodução e a melhoria dos modos e da qualidade de vida e exploração dos recursos naturais das populações tradicionais, bem como valorizar, conservar e aperfeiçoar o conhecimento e as técnicas de manejo do ambiente, desenvolvido por estas populações (BRASIL-SNUC, 2000). 
Mapa: Localização da reserva Alcobaça

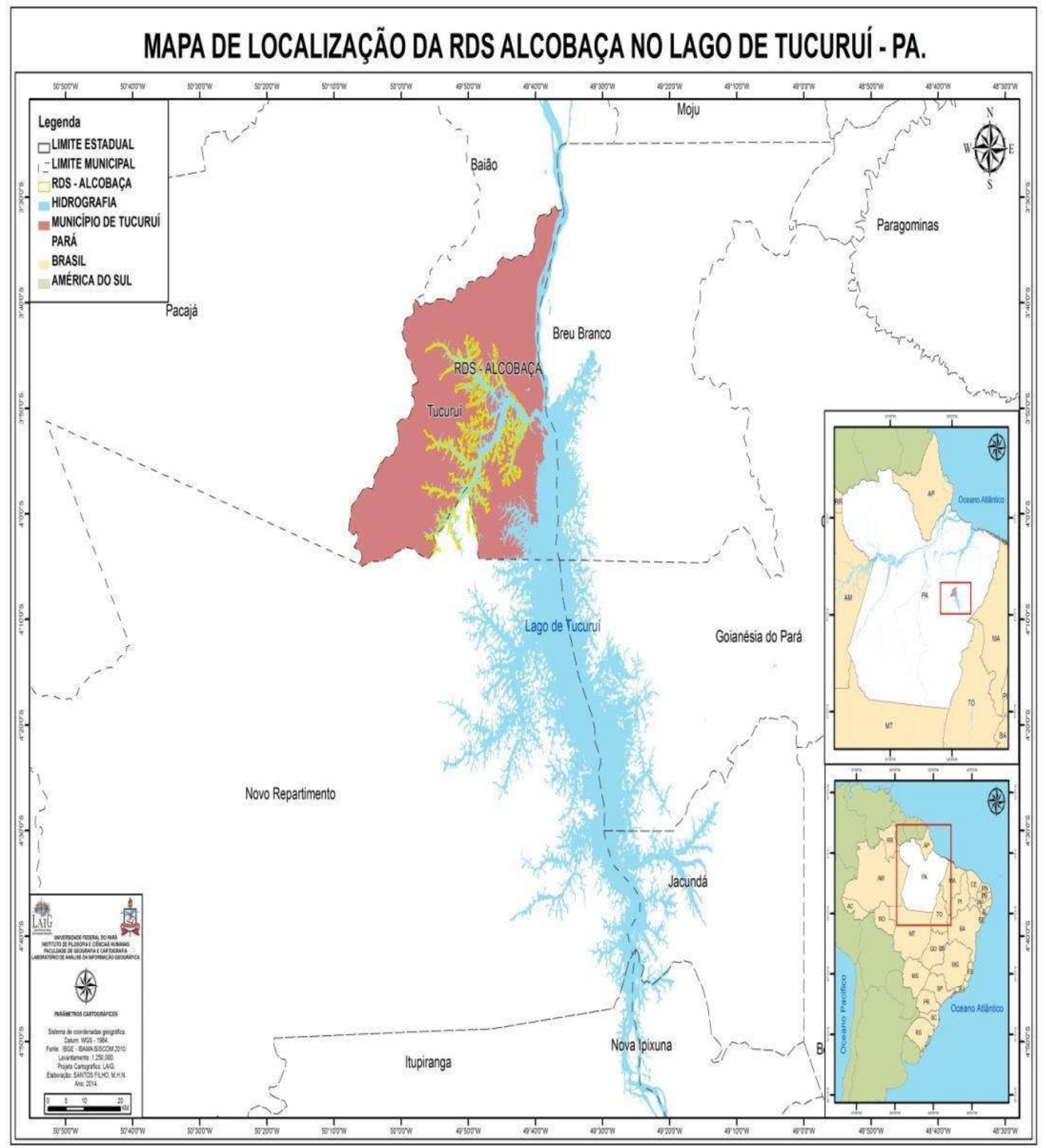

Fonte: Laboratório de Análises de Informação Geográfica-LAIG/UFPA, 2014.

A área total do lago (Figura 2) corresponde a cerca de $100 \mathrm{~km}$ de extensão no sentido norte/sul e $18 \mathrm{~km}$ no sentido leste/oeste, somando aproximadamente 1500 ilhas em seu interior. Essa área abrange os municípios de Tucuruí, Breu Branco, Goianésia, Novo Repartimento, Jacundá, Nova Ipixuna e Itupiranga, todos localizados no estado do Pará. (JATOBÁ, 2006; ARAÚJO e ROCHA, 2008).

Esse empreendimento gerou inúmeros problemas socioambientais obrigando o governo do estado do Pará, em 2002, a partir da Secretaria de Meio Ambiente, a criar o 
mosaico de Unidades de Conservação que se estende por toda a área inundada. O referido mosaico é composto por: uma Área de Proteção Ambiental (APA) que se estende por todo o lago, por duas Reservas de Desenvolvimento Sustentável (RDS) Alcobaça e Pucuruí-Ararão, e pelas duas Zonas de Proteção da Vida Silvestre- ZPVS (ARAÚJO e ROCHA, 2008).

Para os levantamentos de dados que compõem este artigo, foram feitas viagens a campo, nos anos de 2013 e 2014, e realizadas entrevistas com populações que residem nas Unidades de Conservação de Uso Sustentável, no caso as RDS's e que realizam cultivos de diversidade de espécies em áreas determinadas pela gestão das Unidades de Conservação (UC). As análises foram sistematizadas a partir das observações diretas e dos dados coletados nas entrevistas sobre a disponibilidade de recursos e modos de cultivos baseados na organização social, repousando especial atenção sobre como se dá o acesso a esses ecossistemas que se encontram sob a responsabilidade da gestão pública.

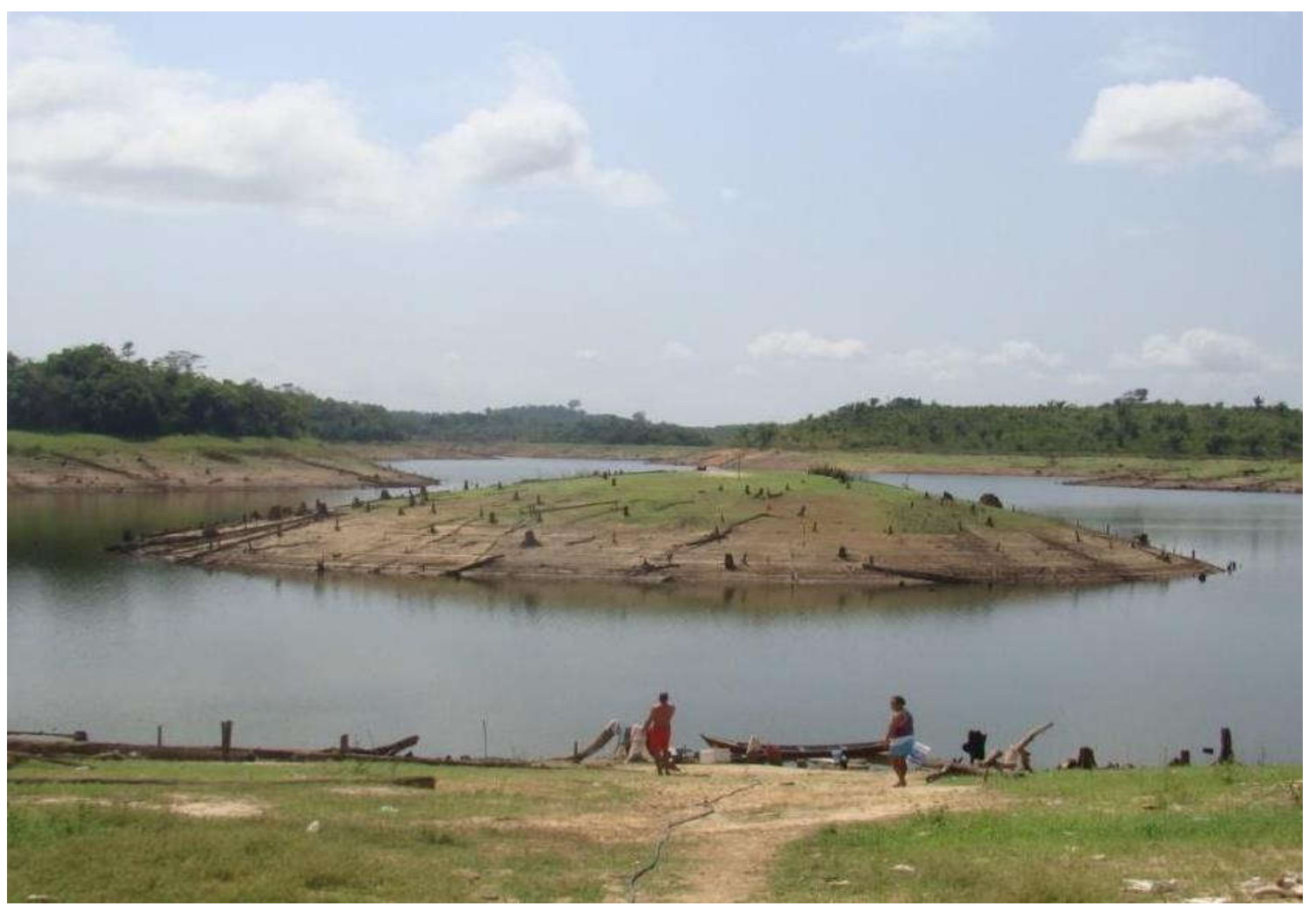

\section{CONSERVAÇÃO AMBIENTAL NO LAGO DA USINA HIDRELÉTRICA}

A população que reside RDS Alcobaça, no lago da Usina Hidrelétrica de Tucuruí, possui uma declaração que atesta que a mesma encontra-se inscrita no Cadastro de Famílias 
de Moradores dessa UC. O referido documento apresenta as coordenadas geográficas da área que cada família reside e está assinado pelo diretor das Áreas Protegidas do lago de Tucuruí.

É nessa área, determinada pela coordenadas geográficas, que a família pode utilizar para o cultivo de determinadas espécies. O programa de germoplasma florestal gerenciado pelas Centrais Elétricas do Norte do Brasil S/A - Eletronorte, já tentou de várias formas inserir o cultivo de espécies, geradas no banco de sementes do programa, nas práticas agrícolas dessas famílias, que desenvolvem uma pequena agricultura familiar.

No entanto, os moradores resistem ao programa, devido à falta de conhecimento sobre as espécies para o cultivo, oferecidas pelo banco de sementes, e pela determinação da área onde devem plantar. Essas determinações impostas pela Eletronorte excluem os conhecimentos das populações, ao passo que não negocia os locais de plantio, definidos exclusivamente pela empresa, desenhando assim uma definição unilateral que, dentro do que descreve Feeny et. al. (1990), resulta em uma baixa possibilidade de êxito para o manejo, não assegurando o uso sustentável dos recursos devido a proliferação de normas e regras restritas a modelos fora do contexto real dessas populações. Além de não levarem em consideração que,

A análise do senso comum, e não necessariamente seu exercício, deve, portanto, iniciar-se por um processo em que se reformule esta distinção esquecida, entre uma mera apreensão da realidade feita casualmente - ou seja lá o que for que meramente e casualmente apreendemos - e uma sabedoria coloquial, com os pés no chão, que julga ou avalia esta realidade.(GEERTZ,1997 p115)

Paralelo a esse modelo de restrição verificado em campo, pode ser observado na região, grandes áreas utilizadas para pecuária (Figura 3). É importante notar que essas áreas compõem a Área de Proteção Ambiental (APA), embora em seu artigo 15 e $\S 1^{0}$ deixa visível que a APA é constituída por terras públicas ou privadas, o que permite a presença de propriedade privada em seu interior, mas obedecendo todos os meios legais, prioritariamente o que rege essa área, pois de acordo com o Sistema Nacional de Unidades de Conservação a Área de Proteção Ambiental é.

É uma área em geral extensa, com um certo grau de ocupação humana, dotada de atributos abióticos, bióticos, estéticos ou culturais especialmente importantes para a qualidade de vida e o bem-estar das populações humanas, e tem como objetivos básicos proteger a diversidade biológica, disciplinar o processo de ocupação e assegurar a sustentabilidade do uso dos recursos naturais (BRASIL-SNUC, 2000

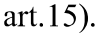


Por outro lado, a fiscalização sobre o cumprimento das regras que devem ser observadas em UC's é pequena diante da pressão externa ao uso e acesso livre dos recursos naturais para essas áreas.

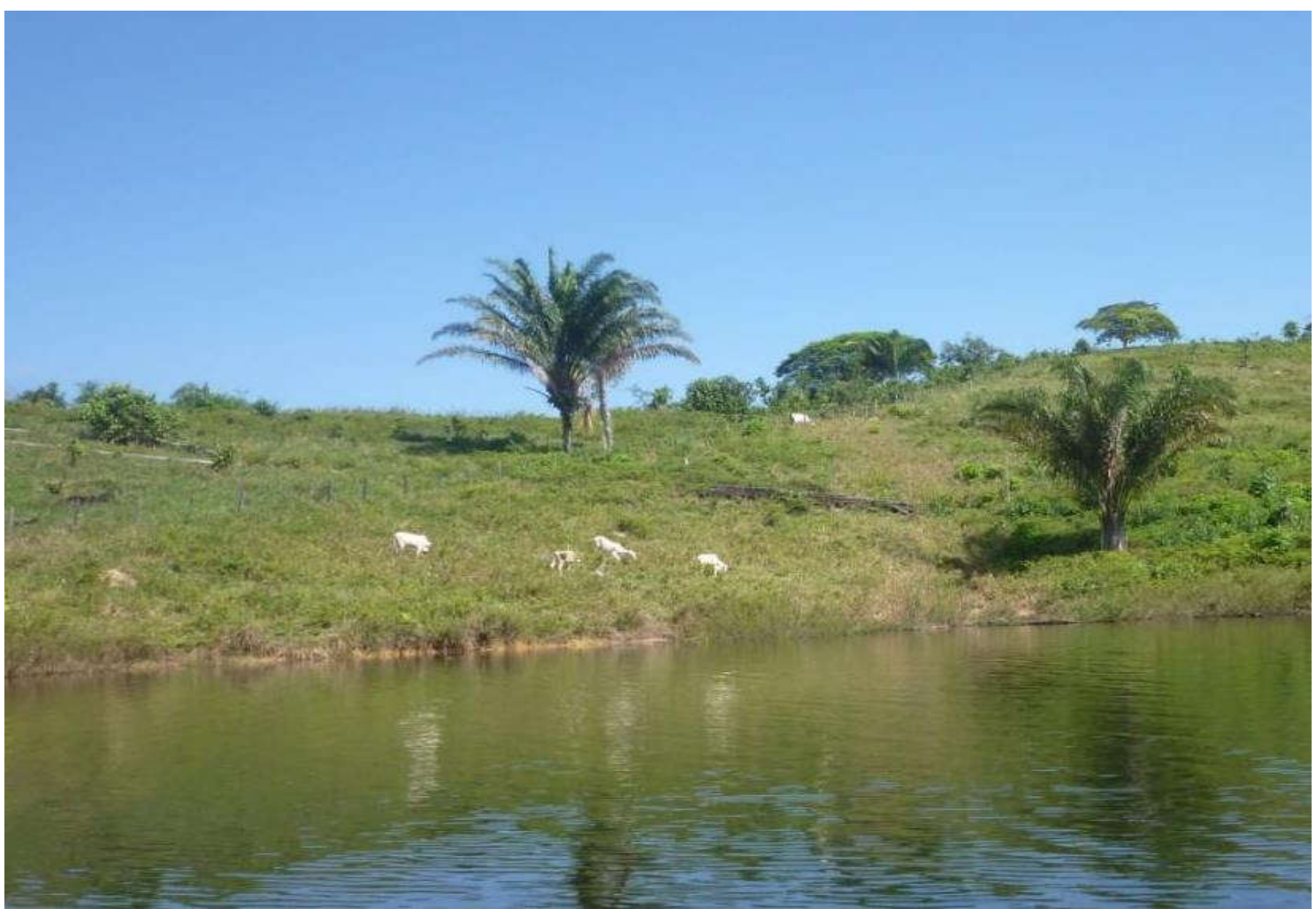

A diversidade de espécies cultivadas mostra que mesmo diante das limitações que a população tem em relação ao uso do solo, conseguem em pequenos espaços desenvolver formas de subsistências numa estratégia de conservação ambiental, não deixando de inserir espécies que fazem parte de seus contextos históricos.

A mandioca - gênero Manihot conforme imagem a seguir é considerada pela população local como um dos produtos mais populares na alimentação, embora tenham acesso a uma área muito pequena para o cultivo da mandioca que poderia acarretar no desgaste do solo e posteriormente prejudicar esse cultivo, os moradores da reserva Alcobaça, buscam diversas alternativas para realizar a produção durante o ano todo. A mandioca é utilizada de inúmeras maneiras pela população envolvendo um conjunto de saberes e práticas singulares que vão desde seu cultivo até o consumo expressando diversidades culturais desses povos, como descrito perfeitamente por Pinto (2002). 
O complexo sistema apresentado pela mandioca abrange um conjunto articulado de aspectos históricos, econômicos e socioculturais que lhe conferem posição peculiar entre os demais produtos agrários produzidos no Brasil. Economia de subsistência para boa parte da população rural, produção artesanal e industrial, relações sociais de produção familiares, comunitárias e/ou assalariadas, alimento básico da população mais pobre, importante componente do sistema culinário brasileiro, tradição histórica e valores culturais, revela múltiplas dimensões da vida social, configurando-se, por isso, como um fato social total (PINTO, 2002 p.14).

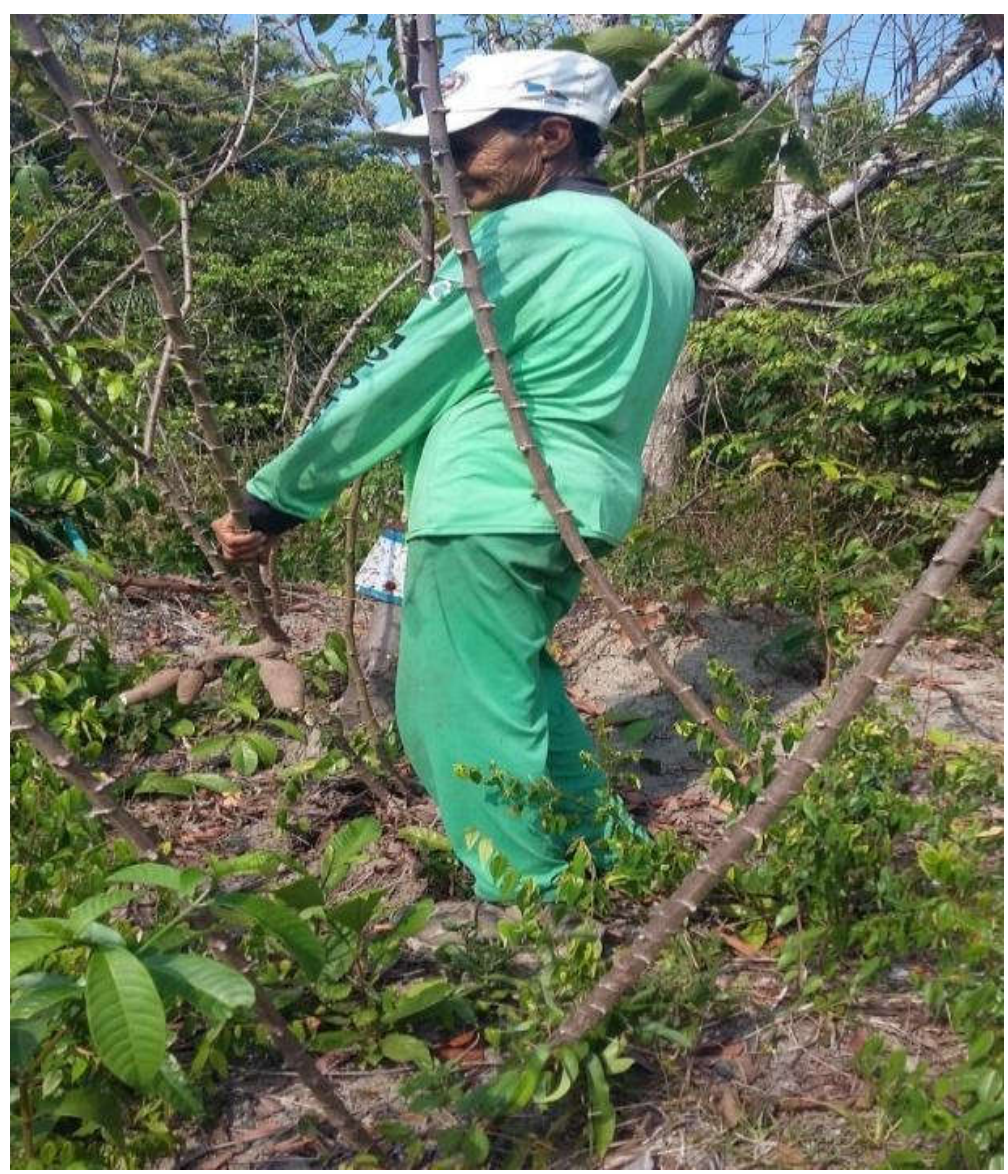

Os saberes locais construídos a partir de todo processo que cerca sobre o açaí - gênero Euterp, como mostra a imagem a seguir, pode ser observado a partir do manejo se dá pelos saberes e pelas práticas das populações que consomem esse fruto. Para os moradores da reserva Alcobaça a periodicidade de remover as folhas secas que caem da palmeira é uma das práticas fundamentais para a manutenção do açaizal, pois essa remoção não pode ser realizada a qualquer momento, pois em determinada época do ano essas folhas precisam ficar no solo para a manutenção dos nutrientes.

Outra prática realizada na manutenção do açaizal se dá pelo caimento dos frutos que germinam, e essa geminação em grande escala pode prejudicar o açaizal, logo esses vegetais que brotaram tem que serem retirados. Embora o espaço seja reduzido para o cultivo do açaí, 
a pequena área que resta à população para essa plantação é manejada de forma em que todos os saberes são colocados em práticas para que o fruto nunca falte, pois assim como a mandioca, o açaí é fundamental na dieta dessa população.

Muitos estudos acerca da etnobotânica têm ganhado destaques nos levantamentos dos conhecimentos associados às plantas medicinais. Conhecimentos esses associados a produção científica e saberes de populações locais, que mesmo diante da implantação da hidrelétrica a população da área de influencia do reservatório não deixou que os diversos impactos atingissem suas práticas de cultivo das ervas medicinais.

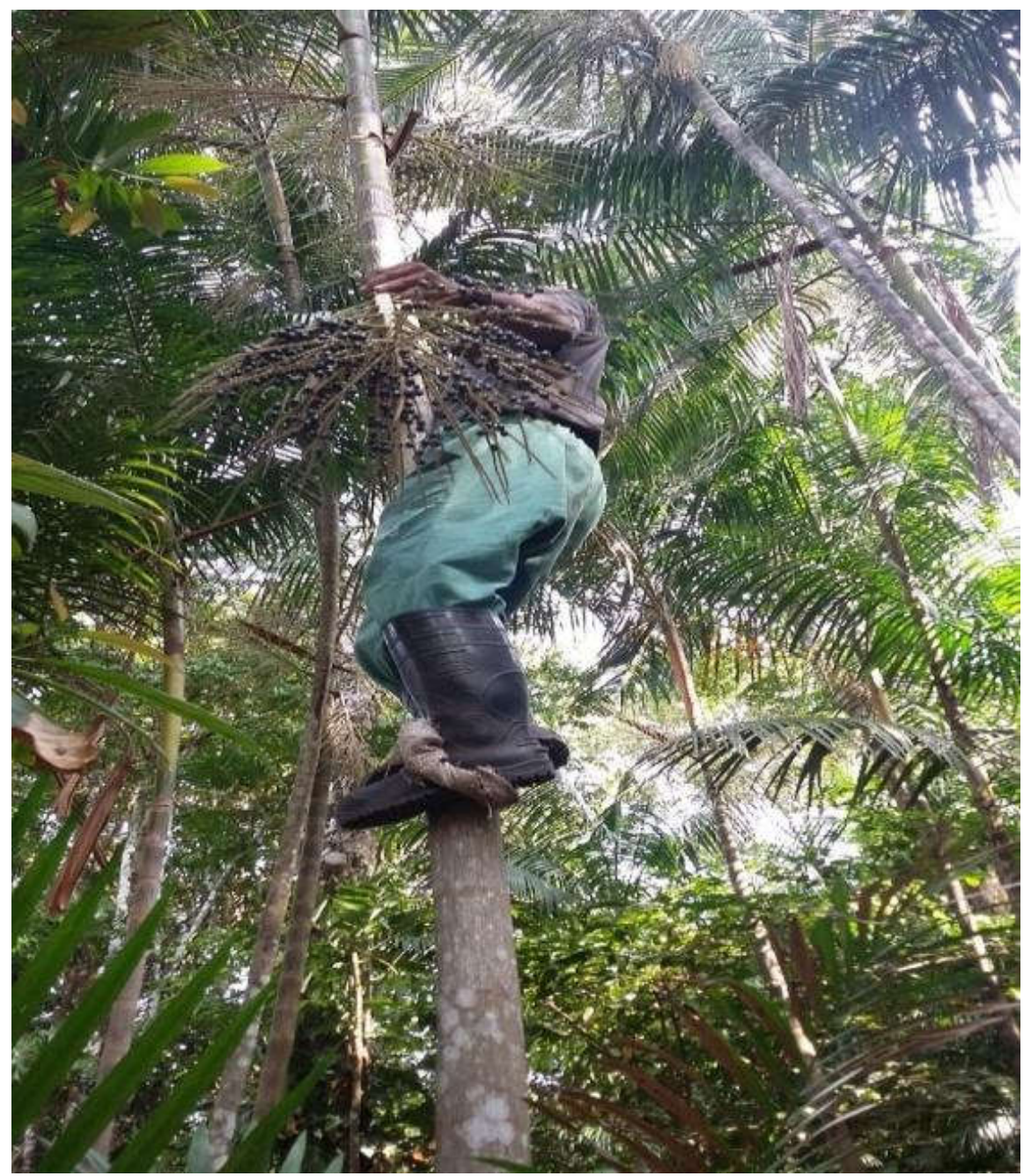


Embora a Eletronorte tente inserir inúmeras espécies, a partir dos projetos de sementes do banco de germoplasma ${ }^{4}$, a população vem resistindo a suas tradições no cultivo das ervas medicinais, conforme imagem adiante, tais como: boldo - Plectranthus, capim marinho Cymbopogon, elixir paregórico - Piper, erva cidreira - Lipea, hortelã - Mentha, mastruz Chenopodium, pariri - Arrabidaea.

Os saberes locais dessa população ultrapassa qualquer forma de imposições, se adequando a realidade dos ecossistemas alterados pela usina hidrelétrica. Relatos das populações residentes mostram a importância do cultivo de cada espécie, onde faz-se necessário trabalhar o termo conservação ambiental abrangendo incluindo os elementos da biodiversidade com relevância para a agricultura e alimentação“ ...não consigo viver sem plantar minha mandioca pra fazer a minha farinha, sem apanhar meu açaí para o meu almoço, sem cuidar da minha horta com todas as minhas plantas para fazer remédios para minha família...”.

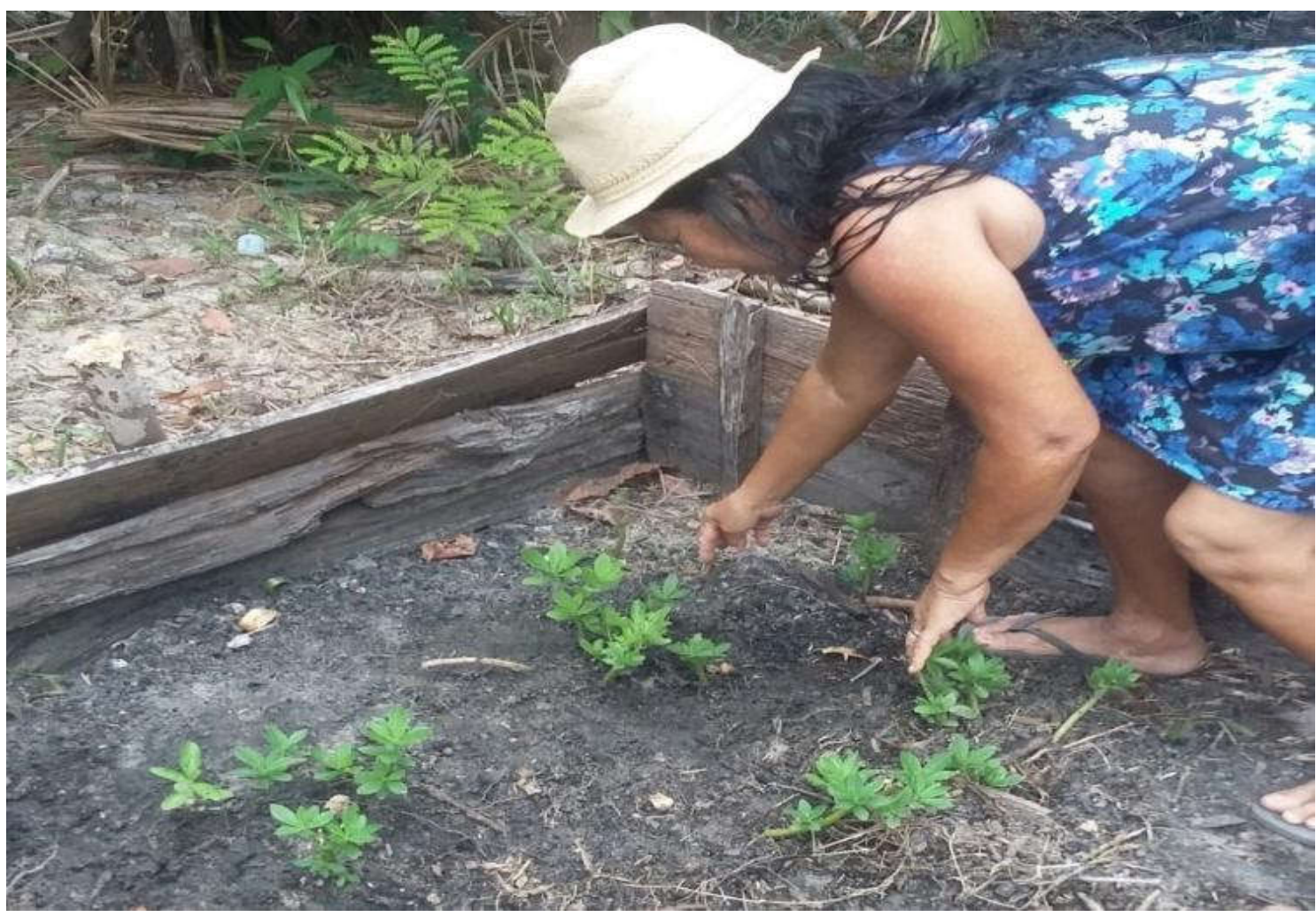

${ }^{4}$ O Programa de Revitalização do Banco de Germoplasma é desenvolvido pela Eletronorte desde 2004 a partir da preservação do material genético de espécies florestais atingidas pela formação do lago. Distribui sementes e mudas para a população locais e indígenas. 
Foi observado no caso em tela que perspectivas para a conservação ambiental devem ser efetivadas, não apenas a partir da imposição da gestão de Unidades de Conservação, nem tão pouco o uso do solo através das propriedades privadas e de forma alguma tornar as área como um recurso de livre acesso. Mas de certa forma juntar o sistema de organização das comunidades com as regras do Estado, chamando também os grandes agricultores como forma de uma gestão de compartilhamentos de recursos nessas áreas ditas protegidas.

Diante dessa diversidade de cultivo realizado pelos moradores do lago de Tucuruí, pode ser observado um processo de mutualismo partindo da ideia de interações ecológicas de Odum (1913) em que as análises das interações populacionais podem ser observadas entre duas espécies, mas, sobretudo, uma relação simbiótica entre variedades de espécies, entre elas, o Homem.

\section{O CULTIVO DE MANDIOCA - Manihot esculenta Crantz NA RESERVA DE DESENVOLVIMENTO SUSTENTÁVEL ALCOBAÇA}

A atenção dada especialmente ao cultivo da mandioca como mostra a imagem mais adiante, configura na importância ímpar na dieta da população local.

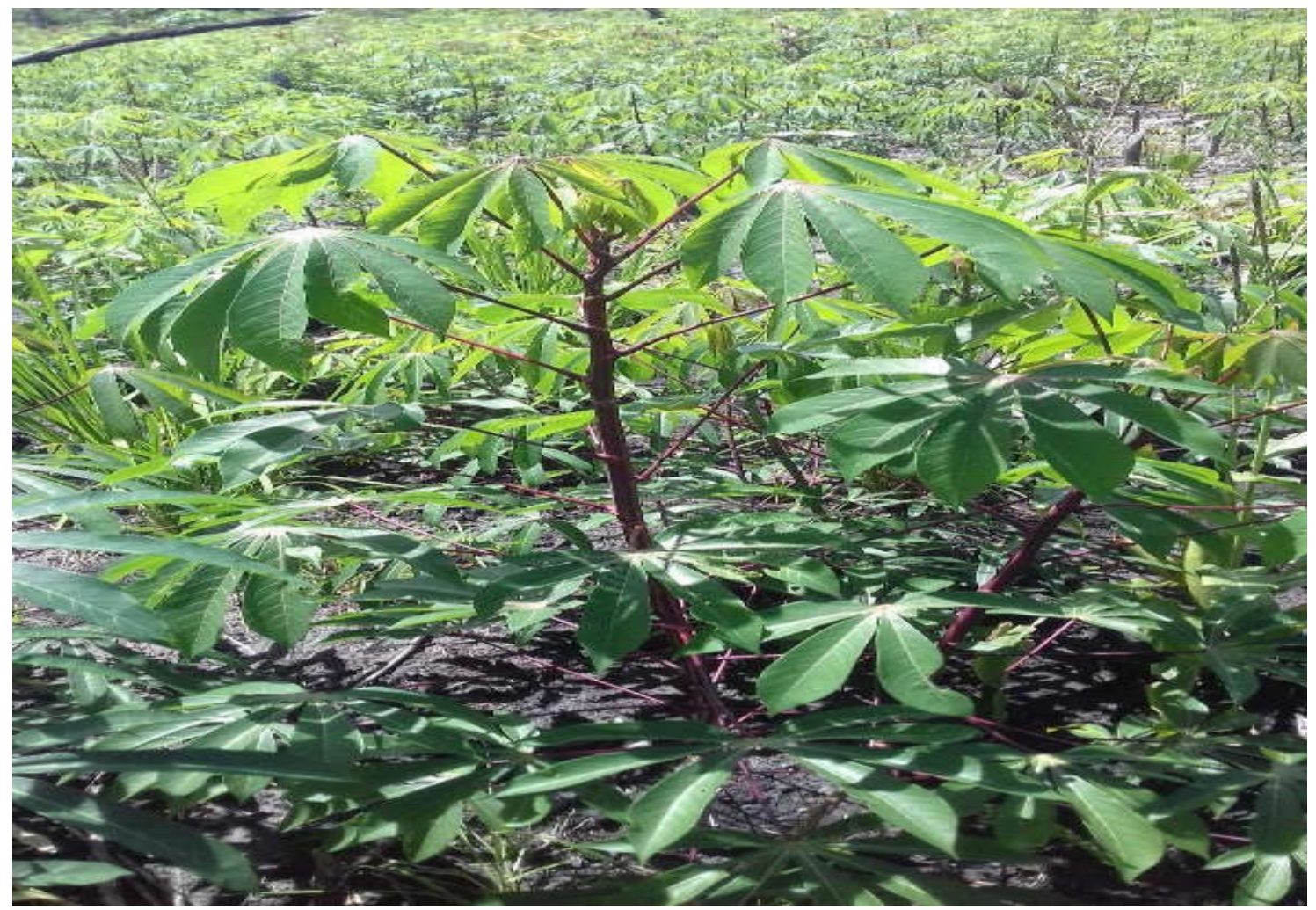


Quando se fala em Amazônia é quase impossível não pensar nos múltiplos derivados da mandioca, que ao longo dos anos vem ganhando destaque nacional e internacionalmente com o boom da tapioca. Enquanto pesquisas sobre o valor nutricional da mandioca são desenvolvidas, as populações amazônicas vêm tradicionalmente retificando a importância dessa raiz em sua dieta.

Embora a população da Reserva de Desenvolvimento Alcobaça no lago da usina hidrelétrica de Tucuruí viva diretamente da comercialização do pescado, esta não consegue dissociar a atividade agrícola a partir do cultivo de mandioca para a produção de diversos alimentos. Da mandioca - Manihot esculenta Crantz a população extrai tradicionalmente o tucupi (suco da mandioca), tapioca e a farinha, atividades essa que perpassa por saberes e práticas milenares, que vai desde o preparo do solo para o cultivo da mandioca até o consumo final.

Considerando o cultivo com os cinco tipos de pousio trazidos por Buserup (1978): cultivo longo ou florestal, arbustivo, curto, anual e múltiplos, pode-se analisar que a população da reserva Alcobaça a partir do cultivo da roça de mandioca, realiza os pousios longo e arbustivo considerados as melhores alternativas da agricultura ecológica, pois o tempo de repouso da terra varia de 6 a 30 anos, permitindo a capacidade de suporte das áreas utilizadas para esta atividade. Esses tipos de cultivos com pousio longo e arbustivo realizado pela população do lago da usina, só foi possível devido a organização social a partir das relações de parentesco (Tabela 1).

Tabela 1. Cultivo com pousio na RDS Alcobaça

\begin{tabular}{|c|c|c|}
\hline & \multicolumn{2}{|c|}{ SABERES E PRÁTICAS TRADICIONAIS NO CULTIVO DA MANDIOCA } \\
\hline & TIPOS DE POUSIO (BUSERUP, 1987) & $\begin{array}{l}\text { POUSIO REALIZADO NA RDS } \\
\text { ALCOBAÇA }\end{array}$ \\
\hline & Longo ou Florestal: De 20 a 30 anos & \multirow{5}{*}{$\begin{array}{l}\text { Longo e arbustivo: trata-se de um } \\
\text { cultivo a partir de relação de parentesco } \\
\text { (consanguíneos e/ou afins), que a partir de } \\
\text { gerações o cultivo é realizado em modelo } \\
\text { cíclico. Há } 17 \text { anos da última área cultivada. }\end{array}$} \\
\hline & Arbustivo: De 6 a 10 anos & \\
\hline & Curto: De 1 a 2 anos & \\
\hline meses. & Anual: Não considerado pousio - apenas & \\
\hline lavouras & $\begin{array}{l}\text { Múltiplos: A área suporta } 2 \text { ou mais } \\
\text { o ano. }\end{array}$ & \\
\hline
\end{tabular}

Fonte: Ester Buserap, 1987 e Pesquisa de campo no lago da UHT, 2014. 
Nesse contexto pode ser observado nos trabalhos de Ravena e Cañete (2012) que destacam em cenários amazônicos a composição e o número de indivíduos familiar determinam a força de trabalho. Em outras linhas, essa composição parte dos entrelaces familiares, onde os saberes tradicionais determinam as práticas, e a arte do saber-fazer determina a ocorrência do pousio longo e arbustivo a partir das tradições. Esses conhecimentos são sistematizados em ciclos no uso dos lotes para cultivos, esses ciclos são realizados a partir do uso das terras a serem cultivadas, onde as roças são produzidas uma de cada vez na área de cada parente. Esse sistema cíclico no cultivo de mandioca em terras de cada membro da família garante um pousio de aproximadamente 17 anos.

Nesses sistemas de pousio um roçado dentro dos aspectos legais - área liberada pela Secretaria de Meio Ambiente e Sustentabilidade nas Unidades de Conservação especialmente em Reservas do lago, atende as necessidades das famílias durante cerca de um ano, pois a fertilidade do solo permite alta na produção, não apenas de mandioca, mas de outras espécies cultivadas, como a melancia, maxixi e a abóbora, como apresenta a imagem a seguir, garantindo os nutrientes da terra e excluindo o processo de monocultura da mandioca.

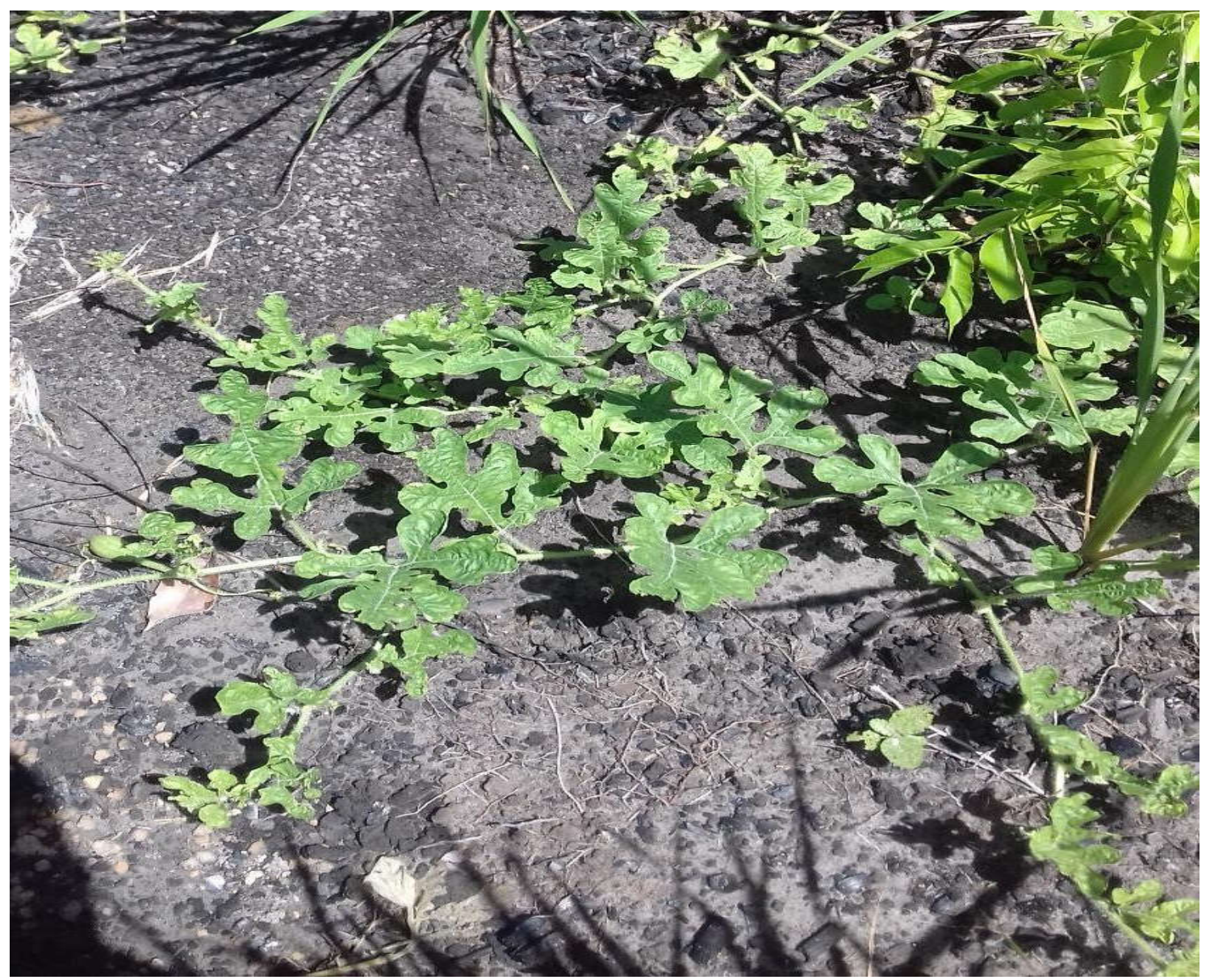


Em geral, as análises construídas partem de um modelo de cultivo que respeite a estabilidade dos ecossistemas, não defende a retomada ao passado, como mostram os novos modelos de agricultura capitalista industrial. Mas apoia a ideia de levar em consideração os conhecimentos tradicionais dos povos e comunidades que há séculos vivem do uso do solo.

Dessa forma, a agroecologia redesenha a nova lógica dos sistemas a partir de um processo de relações ecológicas simbióticas nos sistemas de produção, levando em conta a incorporação dos saberes e das práticas tradicionais preservando a tradição das diversas populações, ao invés de intensificar o uso dos ecossistemas apenas no contexto de produção e consumo.

\section{CONCLUSÕES}

Considerando que mesmo diante de todos os impactos trazidos pelas obras da construção da Usina Hidrelétrica de Tucuruí - UHT, a população que habita a área do reservatório, vem ao longo desses 30 anos readequando seus modos de vida a partir da construção de novas identidades diante de uma nova paisagem com cenários de muitos conflitos socioambientais ao longo do funcionamento da usina.

$\mathrm{Na}$ perspectiva da conservação dos recursos naturais, o modelo do Sistema de Unidades de Conservação imposta pelo Estado, revela que mesmo com essas fortes pressões os moradores da reserva conseguem readequação seus dos modos de vidadas sem comprometer a estabilidade dos recursos, principalmente no que se refere ao uso e acesso às áreas a partir do cultivo da mandioca, do açaí e a horticultura de subsistência.

Nesse sentido, o processo de conservação da ambiental ultrapassa os modelos desenhados por políticas impostas sobre os ecossistemas, vai além das normas e regras do uso e acesso aos bens comuns, mas busca de certa forma as interações entre os conhecimentos que todas as comunidades apreendem com os saberes e as práticas tradicionais.

Assim, ainda falta muito incentivo governamental em políticas para as práticas agroecológicas sustentáveis, respeitando os direitos dos agricultores e a capacidade de suporte dos ecossistemas partindo do conceito de conservação ambiental para a conservação da diversidade biológica e social. 


\section{REFERÊNCIAS}

ALMEIDA, Neila de Jesus Ribeiro; CAÑETE, Voyner Ravena. Recursos Naturais e Cotidiano: População ribeirinha e a gestão da RDS Alcobaça - UHT Tucuruí/PA. TESSITURAS: Revista de Antropologia e Arqueologia, v. 3, p. 191-207, 2015.

ARAÚJO, Aline. R.; ROCHA, Gilberto. M. Unidades de Conservação em Tucuruí/PA como instrumento de Gestão Territorial. In: IV Encontro Nacional da Anppas. Brasília-DF. 2008.

BRASIL . Lei $\mathrm{n}^{\circ}$ 9.985, de 18 de julho de 2000; Decreto $\mathrm{n}^{\circ} 4.340$, de 22 de agosto de 2002. Sistema Nacional de Unidade de Conservação da Natureza - SNUC: 3. ed. aum. Brasília: MMA/SBF, 2003.52p.

BUSERAP, Ester. Evolução agrária e pressão demográfica. Tradução de Oriwaldo Queda; João Carlos Duarte. São Paulo: Hucitec, 1987.

CAÑETE, Voyner; CAÑETE, Thales. Caminhos e alternativas na produção agrícola: uma reflexão sobre as especificidades da Amazônia. $5^{\circ}$ Encontro de Redes Rurais, jun 03 a 06 de junho de 2012, Belém/PA. Disponível em: $<$ http://www.redesrurais.org.br/sites/default/files/Caminhos\%20e\%20Alternativas\%20da\%20 Produ\%C3\%A7\%C3\%A3o\%20Agr\%C3\%ADcola.pdf> Acesso em: 13 jul.2013.

DIEGUES, Antônio Carlos; ARRUDA, Rinaldo. Saberes tradicionais e biodiversidade no Brasil. Brasília: Ministério do Meio Ambiente; São Paulo: USP, 2000.178p.(Biodiversidade4).

FEENY, David; BERKES, Fikret; MCCAY, Bonnie; ACHESON, James. A Tragédia dos Comuns: Vinte e dois anos depois. (The Tragedy of the commons: TwentyTwo years later Human Ecology, 18(1): 1-19, 1990). In. Espaços e Recursos Naturais de Uso Comum. (Orgs) Diegues, Antônio C.; Moreira, André C. NUPAUB: São Paulo, 2001.

FERNANDES, Daniel dos Santos; FERNANDES, José Guilherme dos Santos. A experiência próxima: saber e conhecimento em populações tradicionais. Espaço Ameríndio, v.9, n. 1, 2015. Disponível: http://seer.ufrgs.br/index.php/EspacoAmerindio/article/view/53593/34131. Acesso: 29 out2015.

HARDIN, Garret. The Tragedy of the Commons. Science, 162: 1243-1248, 1968.

PINTO,Maria Dina Nogueira. Mandioca e Farinha: subsistência e tradição cultural. Série Encontros e Estudos. Seminário Alimentação e Cultura-Projeto Celebrações e Saberes da Cultura Popular. Centro Nacional de Folclore e Cultura Popular/FUNARTE/Secretaria do Patrimônio, Museus e Artes Plástico-Ministério da Cultura,2002.

CAÑETE, Voyner; CAÑETE, Thales. Caminhos e alternativas na produção agrícola: uma reflexão sobre as especificidades da Amazônia. $5^{\circ}$ Encontro de Redes Rurais, jun 03 a 06 de junho de 2012, Belém/PA. Disponível: $<$ http://www.redesrurais.org.br/sites/default/files/Caminhos\%20e $\% 20$ Alternativas $\% 20 \mathrm{da} \% 20$ Produ\%C3\%A7\%C3\%A3o\%20Agr\%C3\%ADcola.pdf > Acesso em: 13 jul.2013. 
GEERTZ, Clifford. O saber local: novos ensaios em antropologia interpretativa. Tradução de Vera Mello Joscelyne. Petrópolis, Vozes, 1997.

JATOBÁ, Sérgio Ulisses Silva. Gestão do Território e a produção da socionatureza nas Ilhas do Lago de Tucuruí na Amazônia Brasileira. Tese apresentada ao Centro de Desenvolvimento Sustentável da Universidade de Brasília, 2006.

ODUM, Eugene. Ecologia. Ed.Guanabara Koogan: Rio de Janeiro, 1988.

PINTO, Maria Dina Nogueira. Mandioca e Farinha: subsistência e tradição cultural. Série Encontros e Estudos. Seminário Alimentação e Cultura-Projeto Celebrações e Saberes da Cultura Popular. Centro Nacional de Folclore e Cultura Popular/FUNARTE/Secretaria do Patrimônio, Museus e Artes Plástico-Ministério da Cultura,2002.

SANTILLI, Juliana. Agrobiodiversidade e direitos dos agricultores. Peirópolis: São Paulo, 2009. SOUZA, Vinicius.C.; LORENZI, Harri. Botânica Sistemática. Instituto Platarum, Nova Odessa, 2009. 